\title{
The Effect of the Graphic Organizer Strategy on University Students' English Vocabulary Building
}

\author{
Arwa N. Al-Hinnawi ${ }^{1}$ \\ ${ }^{1}$ Zarqa University College, Al-Balqa' Applied University, Zarqa, Jordan \\ Correspondence: Arwa N. Al-Hinnawi, P. O. Box 11974, 13118 Hay Al-Hussein Post Office, Zarqa, Jordan. Tel: \\ 962-79-9266659. E-mail: Arwa_Alhinnawi@yahoo.com
}

Received: September 17, 2012 Accepted: October 8, 2012 Online Published: October 19, 2012

doi:10.5539/elt.v5n12p62 URL: http://dx.doi.org/10.5539/elt.v5n12p62

\begin{abstract}
This study aimed at investigating the effect of the graphic organizer strategy on vocabulary building and vocabulary incremental growth of Jordanian university EFL students. One hundred and two students participated in the study which lasted for one academic semester of four months. Each student enrolled in one of two intact and equally-sized classes of a general English Language course. One of the classes was assigned to an experimental group, whose students were taught eight specific features of vocabulary items using the GO strategy. The eight features were the word's spelling, pronunciation, part of speech, meaning in the first language, meaning in the foreign language, synonym, antonym and using it in an example sentence. The other class was assigned to a control group, whose students were taught the same vocabulary items using traditional instruction. A pre-test and a post-test were administered to all students whose responses were analyzed using adjusted means, standard errors and an ANCOVA. Results revealed that the experimental group students outperformed those students in the control group concerning their vocabulary building. To decide whether the GO strategy had an incremental growth in students' vocabulary building, students of both groups sat for three separate evaluative tests. Students' responses were analyzed using Microsoft Excel sheets and results showed that this strategy significantly improved students' vocabulary growth over time.
\end{abstract}

Keywords: EFL vocabulary building, the graphic organizer strategy, university students, vocabulary instruction, incremental growth

\section{Introduction}

Teachers are constantly faced with introducing new vocabulary to students in all subject areas (Norfleet, 2002). Words that seem common to teachers can be a puzzle to students. Thus, the teacher is faced with the dilemma of how to make new subject matter and vocabulary meaningful to his/her students. Because vocabulary acquisition is crucial to academic development, the teaching situation becomes more difficult when the subject matter is English. And many native or non-native English speakers will want to improve and enlarge their English vocabulary whether at the school, college or the university level (Grieser, 2009). What makes the situation even more difficult is teaching new vocabulary of English as a foreign language (hereafter EFL). As an instructor of English for many years, the researcher noticed that her students' knowledge of EFL vocabulary was very limited, no matter how much she emphasized the importance of vocabulary for their academic achievement. They used to show little attention and effort to studying vocabulary items that they encounter in their English textbooks. In an attempt to encourage them to gain more vocabulary knowledge, she used to employ different separate classroom activities such as giving the meaning of the word in the first language, locating the word in a text and making use of the context clues. Yet, only some students gained vocabulary building which was very limited in size and quality.

\subsection{Vocabulary Building}

Pittman (2003) considers EFL vocabulary building as the most important aspect of language learning, and Martin (1991) asserts that building a good vocabulary is a lifetime project for most educated people. In addition, confidence with vocabulary goes a long way in the four language skills of reading, writing, listening and speaking and with standardized test-taking (Pittman, 2003). Therefore, a student's existing language proficiency in vocabulary, grammar and idioms plays an essential role in text comprehension, for example (Xiao-hui, Jun, \& Wei-hua, 2007). Moreover, understanding new vocabulary should be meaningful to students by connecting these 
words to something they already know (Iwai, 2007).

EFL vocabulary building, then, becomes a need and a challenge, at the same time, for a large number of students who study English only at schools and universities with few chances to use it outside the academic context. This notion is most important because most if not all vocabulary development, in both the first and the foreign or second languages, occurs as learners attempt to comprehend written input (Pulido, 2004); and because extensive reading is commonly proposed as a way for EFL readers to expand their vocabulary (Dycus, 1997). A limited expansion, however, may be achieved by many EFL students, such as Jordanian university ones, majoring in scientific specialties where they have to study their courses in English as a foreign language. In such a case, they may acquire the scientific vocabulary related to their specialties but not other general, everyday communicative vocabulary items that are used to convey complete personal ideas. That is why there is a pressing need among these students to build and improve their vocabulary all the time if they are to pass their exams in English and then pursue their future careers.

\subsection{Vocabulary Instruction}

Students with poor vocabulary items need strong and systematic educational support to become successful independent word learners. Thus, teachers should improve vocabulary instruction and provide strategies to help students deal with the increase in new and difficult words (Hall \& Sabey, 2007). In order to achieve a deeper understanding of newly taught words, Stirling (2003) and Templeton and Pikulski (1999) argue that teachers should encourage students to record and memorize vocabulary items by following several steps and principles such as employing a strategy that ensures organizing the vocabulary items to be taught; learning the vocabulary item accompanied with its meaning in the mother language, its spelling, pronunciation, synonym, antonym, grammatical behaviour, associations, collocations and register; and recycling the vocabulary items many times, that range from five to sixteen times, in order to be comfortable and confident enough that students will use them themselves. In addition, and based on a convincing body of research, Templeton and Pikulski (1999) state that effective vocabulary instruction includes two major components which are direct instruction, and directly teaching specific words and their meanings.

There is definitely reason to reassess arguments against direct vocabulary instruction and to look for effective ways to balance vocabulary learning among EFL/ESL students through direct instruction and incidental exposure (Dycus, 1997). Direct instruction involves determining which words should be taught, how they are taught, and when they are taught (Hall \& Sabey, 2007; Templeton \& Pikulski, 1999). Deciding which words to teach is considered important because words can be classified into three categories (Hall \& Sabey, 2007). The first includes words that students learn as part of their daily living and interactions with the language; the second category includes words which are likely to be unfamiliar to students but would be useful for them to know in order to be successful language users; while the third category includes the specific technical words which should be introduced as needed to understand the topic of study. Hall and Sabey suggest that the words of the second category should be the focus of most vocabulary instruction.

As for how to teach words, Hall and Sabey suggest that vocabulary instruction should be conducted in a frequent, rich and extended manner. It is frequent when it allows students to engage with the target words in a minimum of eight to ten meaningful experiences; it is rich when it goes beyond a quick definition to include associations and relationships between words; and instruction is described as extended when it includes studying the target words beyond the classroom setting. Such features of vocabulary instruction could enable students to effectively build semantic connections between words through using graphic aids and organizers.

\subsection{Using Graphic Organizers in Vocabulary Instruction}

Underlying graphic organizers (hereafter GOs) is the theoretical construct that the visual and verbal organizational structure of the diagram consolidates information into a meaningful whole (Horton, Lovitt \& Bergerud, 1990). Hence, students do not have the impression that they are being taught a series of unrelated terms, facts, or concepts. Furthermore, visuals seem to enhance retention and recall of vocabulary (Sigueza, 2005; Stirling, 2003). This notion is important because the world is moving into an era in which visual literacy is as important as language/textual literacy (Kang, 2004). Thus, Kang adds that EFL teachers should explore and exploit spatial instructional strategies to enhance learning and instruction. The graphic organizer strategy (hereafter the GO strategy) can be utilized in teaching vocabulary, among other courses, to EFL students (Kang, 2004; London, 1999).

Kang (2004) defines a graphic organizer as a creative technique used to present complex information and convert it into a simple and meaningful graphic display of the relationships between concepts. GOs can be used by students, on the one hand, as a study tool to better understand vocabulary meanings and then assess or review, 
for a test, any new vocabulary items learned in a subject area. Teachers, on the other hand, can use the GO prior, during or following teaching a topic to organize the concepts taught. Suitable GOs can be created or chosen by teachers alone, students alone, or both, to teach a certain set of vocabulary. GOs need to be as simple, clear, direct and teachable as possible (Jiang \& Grabe, 2007). Mercuri (2010) confirms that GOs are powerful; they can be part of a supportive classroom environment and integrative instruction; and they can be easy to implement tools that allow teachers to examine students' learning on a particular topic, assess ongoing learning, and design and modify instruction to meet students' needs.

Many different types and examples of these GOs are identified and described in the literature such as conceptual mapping, conceptual frames, networking (Dickson, Simmons \& Kameenui, 1995), KWL, word maps, the knowledge Rating Scale (Gilbertsen, 2002), semantic word maps (Hall \& Sabey, 2007), semantic mapping (Iwai, 2007; Zaid, 1995), definitions, process and sequence, timeline, description and classification, argument (Jiang \& Grabe, 2007), Venn diagrams, semantic maps, spider maps, concept maps, matrix organizers, network trees (Kang, 2004), charts, semantic webs, and word webs (Templeton \& Pikulski, 1999).

\subsection{Review of Related Research}

Research has shown that GOs have a positive effect on a student's ability to learn new vocabulary. A survey of research on the effect of the GO strategy on vocabulary building revealed that most of the relevant studies are limited to native English-speaking students. Horton et al. (1990) found that GOs were most effective with nondisabled college students when they were used to present vocabulary. Fisher, Frey and Williams (2002) also found that both strategies of the GO and vocabulary instruction proved to be effective in improving their 2200 school students' achievement during the period of the study which lasted for three years. However, Smith (2002) did not find any significant differences in his seventh-grade students' vocabulary development due to the use of GOs.

A review of scientifically based research on using GOs in instruction which was prepared by The Institute for the Advancement of Research in Education (IARE) in 2003 included 29 research studies. The review showed that using GOs as a tool to support students' thinking and learning processes helped them develop vocabulary. The review also revealed that one study (Brookbank et al., 1999, as cited in IARE, 2003) and a meta-analysis of 23 studies (Moore \& Readence, 1984, as cited in IARE, 2003) concluded that GOs moderately affected vocabulary test scores. In addition, Bos and Anders (1990, as cited in Howard \& Ellis, 2005) found that their school students gained greater vocabulary learning when they used semantic mapping. Furthermore, Mercuri (2010) found that her elementary students enhanced their vocabulary acquisition when teachers used GOs in an integrative manner.

As for the effect of the GO strategy on EFL students' vocabulary building, only three studies were conducted, the first was done by Zaghlool (2004), and the second by Nilforoushan (2012), while the third was done by Tsubaki (2012), all of which resulted in positive effects of GOs on vocabulary achievement. Zaghlool found that semantic mapping positively affected first scientific secondary students' achievement of lexical items. Additionally, Nilforoushan found that her intermediate EFL students, who were taught vocabulary through semantic mapping, performed better on the vocabulary achievement test than those students being taught in the no-semantic manner. Similarly, Tsubaki found that with the high involvement load, GOs yielded more vocabulary retention among university and college Japanese students in the EFL environment. Yet, determining the effectiveness of GOs for vocabulary learning was only mildly successful as forcing greater involvement load proved to be challenging.

The results of the studies reviewed above, with two exceptions, provided evidence that the GO strategy helped vocabulary building among school students whether native or non-native English-speaking students. Only two of these studies involved university EFL students and only one study involved Jordanian school EFL students but not Jordanian university students. In addition, none of these studies investigated the incremental growth in vocabulary building due to the use of the GO strategy. This leaves much room for further investigations that specifically deal with the effect of the GO strategy on Jordanian university EFL students' vocabulary building and on the incremental growth in their vocabulary building.

\subsection{Purpose of the Study}

This study aimed at answering the following questions:

1. What is the effect of the GO strategy on Jordanian university EFL students' vocabulary building?

2. What is the effect of the GO strategy on Jordanian university EFL students' incremental growth in vocabulary building? 


\section{Method}

\subsection{Subjects}

This study involved all the university students who enrolled a general English/1 course at Zarqa University College during the first semester of the academic year of 2011/2012. The subjects were 102 students who joined two intact classes which were randomly assigned to an experimental group and a control group with 51 students in each. As for the subjects' knowledge of English before conducting the experiment, they either had passed an online-university-set placement exam, or they had studied a remedial English language course. Their age ranged between eighteen and twenty-two.

\subsection{Material Studied}

The material taught to students in both experimental and control groups included all the vocabulary items of the units needed for passing their course. Approximately 1000 vocabulary items, which were listed in a specific wordlist section in their textbook (Hutchinson, 2001), were available for each student to review, study and use during the experiment. Students of both groups were required to study vocabulary items on daily basis, with ten specified items each day. The specified items were the same for students of both groups. The study lasted for one full semester with one session per week.

\subsection{Instructional Treatments}

\subsubsection{Vocabulary Instruction through Using the GO Strategy}

To implement this instruction, the experimental group students were given the first several sessions to orient and train them on EFL vocabulary building through the use of the GO strategy following four steps; namely, preparation, presentation, practice and evaluation. In the preparation step, students were instructed on how to learn each of the vocabulary items as they appear in the different units and the wordlist in terms of eight of its features; namely, spelling, pronunciation, part of speech, meaning in the first language, meaning in the foreign language, synonym, antonym and using it in an example sentence. This step involved training students on learning and recognizing each feature on its own first. Thus, in order to train students on how to write the phonetic transcription of each item, for example, they were taught the different symbols of the International Phonetic Alphabet. The different parts of speech in English were also discussed to enable students to identify the part of speech of each item, and so on and so forth. In addition, they were trained on using English-English dictionaries and English-Arabic dictionaries for identifying any features they might doubt.

In the presentation step, GOs were introduced to students like a normal classroom lesson plan, with the researcher showing them the different kinds of GOs and their features, the advantages of GOs, creating a GO, modelling how to utilize a GO, and guiding students through a GO assignment with their participation. The GO that was employed for the study was the semantic word map that placed the vocabulary item to be learned in a circle at the center of the GO with all the eight word features written in larger circles around that item.

In the practice step, the researcher guided the students to apply what they learned inside and outside the classroom to cover all the vocabulary items in the whole studied material. To implement this step, the researcher got involved in checking and correcting, when needed, students' individual work on GO assignments. This guided practice needed the researcher's close supervision which gradually faded out as the training went on and the students began to practice independently.

Evaluation step covered having and marking students' daily-filled out GOs concerning all the vocabulary items to be learned. Marked GOs were given back to students in order to study them for further evaluation as the experiment went on. Students were told that they will be tested on any vocabulary items they learn to measure their vocabulary building.

\subsubsection{Traditional Vocabulary Instruction}

To implement the traditional instruction, the students of the control group were taught all the vocabulary items and their meanings in the first language as they appear in the different units and in the wordlist. Students were also asked to study those items outside the class. In addition, they were encouraged to use English-Arabic dictionaries but without any kind of training. They were allowed to ask and consult the researcher about the meaning of any item anytime they wish.

\subsection{Procedures and Instruments}

Students of both groups were pre-tested on their EFL vocabulary knowledge before the study began. Then the two instructional treatments were applied. After finishing the first month of the study, all students sat for an evaluation test. Another test was administered at the end of the second month and a third test was administered at 
the end of the third month. The questions of each evaluative test covered two or three learned features of the vocabulary items. After completing the treatments, all students were post-tested. Hence, five different tests were administered to each student in both groups. Each of those five tests consisted of 20 multiple choice questions with a total score of 20 marks, one mark for each correct answer. In order to guarantee the students' seriousness, they were told that all the tests would be part of the requirements of the class work mark. All the tests were validated by three university professors. In addition, the tests' reliability was ensured by administering them all to a group of 30 students outside the study sample and alpha for each one of them was more than 0.90 .

\subsection{Design and Statistical Analyses}

The design of this research is quasi-experimental where vocabulary items were taught to the experimental group students using the GO strategy while they were taught to the control group students using the traditional instruction. The independent variable was the GO strategy and the dependent variables were EFL vocabulary building and incremental growth in EFL vocabulary building. In order to analyze the data of the study, the researcher used the Statistical Package for the Social Sciences (SPSS) to calculate descriptive statistics (adjusted means and standard errors) and inferential statistics (ANCOVA), in addition to Microsoft Excel sheets for other needed calculations.

\section{Results}

\subsection{The Result Related to the First Question}

To answer the first question of the study, relating to whether the GO strategy had an effect on Jordanian university EFL students' vocabulary building, the adjusted means and standard errors of the students' scores on the vocabulary building test for both experimental and control groups were computed, and they are shown in Table 1.

Table 1. Adjusted means and standard errors of students' scores on the vocabulary building test

\begin{tabular}{llll}
\hline Group & $\mathrm{N}$ & Adjusted mean & Standard error \\
\hline Experimental & 51 & 11.291 & 0.171 \\
\hline Control & 51 & 8.919 & 0.173 \\
\hline
\end{tabular}

As shown in Table 1, the adjusted mean score of the experimental group students is 11.29 and the standard error is 0.17 , while the adjusted mean score of the control group students is 8.92 and the standard error is 0.17 . This table shows that there is a difference of 2.372 between the adjusted means of the students' vocabulary building scores in favour of the experimental group. Therefore, the ANCOVA was used to determine the significance of the difference in the adjusted mean scores between the experimental and control groups on the vocabulary building test. The results are shown in Table 2 .

Table 2. ANCOVA Results of students' scores on the vocabulary building test

Dependent variable: Vocabulary building

\begin{tabular}{llllll}
\hline Source of variation & $\begin{array}{l}\text { Type III sum of } \\
\text { squares }\end{array}$ & df & Mean square & F & Significance \\
\hline Corrected model & $726.185^{\mathrm{a}}$ & 2 & 363.092 & 258.581 & 0.000 \\
\hline Intercept & 44.991 & 1 & 44.991 & 32.041 & 0.000 \\
\hline Pre-test & 725.236 & 1 & 725.236 & 516.486 & 0.000 \\
\hline Code & 123.955 & 1 & 123.955 & 88.276 & 0.000 \\
\hline Error & 140.417 & 100 & 1.404 & & \\
\hline Total & 11408.000 & 103 & & & \\
\hline Corrected total & 866.602 & 102 & & & \\
\hline
\end{tabular}

a. $\quad$ R Squared $=0.838$ (Adjusted $\mathrm{R}$ Squared $=0.835$ )

As shown in Table 2, the F value for vocabulary building is 88.28 . This value is statistically significant at the 0.000 level. This result shows that using the GO strategy was more effective in improving students' vocabulary building than the traditional instruction. 


\subsection{The Result Related to the Second Question}

In order to answer the second question, relating to the effect of the GO strategy on Jordanian university EFL students' incremental growth in vocabulary building, students' vocabulary building in both groups was measured by using Microsoft Excel sheets to compare students' scores on the five different tests following two steps. In the first step, students' scores on each test were compared to their scores on the following test to find out whether the students of each group gained any growth in their scores from one test to another. In the second step, the means of the results of the first step computation were measured to compare the growth gained in the experimental group students' scores as opposed to the control group students' scores. The results are shown in Figure 1, where the vertical axis refers to the percentage of growth in students' scores and the horizontal axis refers to the number of students in each group (i.e. 51).

As shown in Figure1, it can be noticed that almost all experimental group students gained growth in their mean scores, while growth in the control group students' scores is not that obvious. To be more specific, further computation was run concerning the percentage of students who gained growth of $40 \%$ or more. This percentage was taken as the base because it was the highest among the control group students. It was found that $43 \%$ (i.e. 22 out of 51 students) of the experimental group students gained growth of $40 \%$ or more in their mean scores, while only $2 \%$ (i.e. 1 out of 51 students) of the control group students gained the same percentage of growth. In addition, it was found that $41 \%$ (i.e. 21 out of 51) of the experimental group students gained growth between $20 \%-39 \%$, while only $2 \%$ (i.e. 1 out of 51 ) of the control group students gained the same percentage of growth. These results mean that using the GO strategy was more effective in achieving incremental growth in vocabulary building than the traditional instruction.

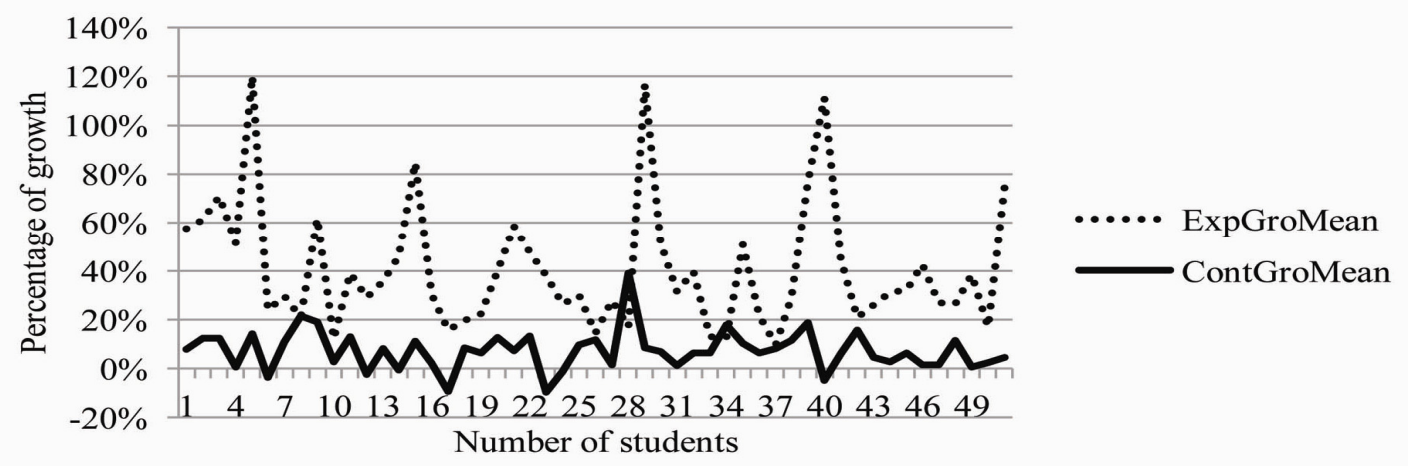

ExpGroMean= mean scores of experimental group students' growth from the first test to the fifth.

ContGroMean= mean scores of control group students' growth from the first test to the fifth.

Figure 1. Means of students' scores on evaluating vocabulary building growth tests

\section{Discussion}

The result related to the first question, concerning whether the GO strategy had an effect on Jordanian university EFL students' vocabulary building, showed that the GO group students had higher scores in vocabulary building tests. This result was in line with the findings of Nilforoushan (2012) and Zaghlool (2004). These higher scores could be attributed to three reasons. First, providing those students with direct and explicit instruction on vocabulary building techniques might have enabled them to improve their vocabulary repertoire in terms of the learned features of each vocabulary item. In other words, students learned all eight features together for each vocabulary item they came across; that is, its spelling, pronunciation, part of speech, meaning in the first language, meaning in the second language, synonym, antonym, and using it in a sentence. The second reason might be the use of the GO strategy to teach different vocabulary items. This strategy might have enabled those students to visually see all learned features as important parts of the same vocabulary item that they were trying to learn. This reason is justified by the notion that today's students are more like visual learners who had grown up on using video games and computers to get new knowledge. The third reason for the higher scores of the GO group students might be the length of the study which lasted for one full academic semester. In such a long period of time, those students had the chance to practice and actually apply building their vocabulary through using the GO strategy, all done in a repetitive manner. As the semester went on, the researcher noticed that they were becoming better autonomous learners. 
As for the result related to the second question, concerning the effect of the GO strategy on Jordanian university EFL students' incremental growth in vocabulary building, it showed that the experimental group students had higher incremental growth in their vocabulary building. This positive result could be attributed to two reasons. First, using the GO strategy might have enabled those students to develop their vocabulary building through a visual representation, not by rote learning of separate abstract concepts. The second reason is that learning all the eight vocabulary features might have broadened those students' knowledge of the different vocabulary items they encountered and enhanced their skills of acquiring that knowledge when needed. This is most important because students in the traditional instruction memorized vocabulary items with their meanings in the first language only without considering any other features.

\section{Conclusions}

The results of the study suggested that the GO strategy was more effective than the traditional instruction in developing vocabulary building of Jordanian university EFL students. It also revealed that the GO strategy achieved incremental growth in those students' vocabulary building over time. Yet, these conclusions need further research where the GO strategy can be incorporated into the different EFL language courses at the university level. Another research area of interest may be replicating this study with an increase in the sample size for an extended period of time, or replicating it with other sample types of students such as school students, struggling students and disabled students in addition to male students as opposed to female students, or children as opposed to adults.

\section{References}

Dickson, S. V., Simmons, D. C., \& Kameenui, E. J. (1995). Text organization and its relation to reading comprehension: A synthesis of the research. The National Center to Improve the Tools of Educators. Retrieved from http://idea.uoregon.edu/\%7Encite/documents/techrep/tech17.html

Dycus, D. (1997). Guessing word meaning from context: Should we encourage it? Literacy Across Cultures, 1(2), $1-7$.

Fisher, D., Frey, N., \& Williams, D. (2002). Seven literacy strategies that work. Educational Leadership, 70-73.

Gilbertsen, C. (2002). Importance of graphic organizers in vocabulary development. Retrieved from http://www.ehow.com/about_6306122_importance-graphic-organizers-vocabulary-development.html

Grieser, R. (2009). How to develop the English vocabulary. Retrieved from http://www.ehow.com/how_7921124_develop-english-vocabulary.html

Hall, K. M., \& Sabey, B. L. (2007). Focus on the facts: Using informational texts effectively in early elementary classrooms. Early Childhood Education Journal, 35, 261-268. http://dx.doi.org/10.1007/s10643-007-0187-2

Horton, S. V., Lovitt, T. C., \& Bergerud, D. (1990). The effectiveness of graphic organizers for three classifications of secondary students in content area classes. Journal of Learning Disabilities, 23(1), 12-29.

Howard, P., \& Ellis, E. (2005). Summary of major graphic organizer research findings. Retrieved from http://www.GraphicOrganizers.com

Hutchinson, T. (2001). Life Lines: Pre-intermediate. Oxford: Oxford University Press.

Iwai, Y. (2007). Developing ESL/EFL learners' reading comprehension of expository texts. The Internet TESL Journal, 13(7), 1-5. Retrieved from http://iteslj.org/Techniques/Iwai-ExpositoryTexts.html

Jiang, X., \& Grabe, W. (2007). Graphic organizers in reading instruction: Research findings and issues. Reading in a Foreign Language, 19(1), 1-22.

Kang, S. (2004). Using visual organizers to enhance EFL instruction. ELT Journal, 58(1), 58-67. http://dx.doi.org/10.1093/elt/58.1.58

London, J. (1999). How to use graphic organizers to teach vocabulary. Retrieved from http://www.ehow.com/how_7738997_use-grphic-organizers-teach-vocabulary.html

Martin, D. (1991). How to be a successful student. Retrieved from http://www.marin.cc.ca.us/\%7Edon/Study/7read.html

Mercuri, S. P. (2010). Using graphic organizers as a tool for the developments of scientific language. Gist Education and Learning Research Journal, 4(1), 30-49.

Nilforoushan, S. (2012). The effect of teaching vocabulary through semantic mapping on EFL learners' 
awareness of the affective dimensions of deep vocabulary knowledge. English Language Teaching, 5(10), 164-172. http://dx.doi.org/10.5539/elt.v5n10p164

Norfleet, M. (2002). Importance of graphic organizers in vocabulary building. Retrieved from http://www.ehow.com/abou_6464066_importance-graphic-organizers-vocabulary-building.html

Pittman, W. (2003). Building vocabulary through prefixes, roots and suffixes. The Internet TESL Journal, 9(7), 1-2. Retrieved from http://iteslj.org/Techniques/Pittman-BuildingVocabulary.html

Pulido, D. (2004). The effect of cultural familiarity on incidental vocabulary acquisition through reading. The Reading Matrix, 4(2), 20-47.

Sigueza, T. (2005). Graphic organizers. Colorin Colorado. Retrieved from http://www.colorincolorado.org/article/13354/pdfs/articles/gfxorg_concdef.pdf/

Smith, J. J. (2002). The use of graphic organizers in vocabulary instruction (ERIC Document Reproduction Service No. ED463556). Retrieved from http://www.eric.ed.gov/ERICDocs/

Stirling, J. (2003). Helping students to learn the vocabulary we teach them. English Language Garden, 1-2. Retrieved from http://www.elgweb.net/index.html

Templeton, S., \& Pikulski, J. J. (1999). Building the foundations of literacy: The importance of vocabulary and spelling development. Houghton Mifflin Company. Retrieved from $\mathrm{http} / / / \mathrm{www} . e d u p l a c e . c o m / \mathrm{rdg} / \mathrm{hmsv} / \mathrm{index} \cdot \mathrm{html}$

The Institute for the Advancement of Research in Education (IARE). (2003). Graphic organizers: A review of scientifically based research. Portland: Inspiration Software, Inc.

Tsubaki, M. (2012). Vocabulary learning with graphic organizers in the EFL environment: Inquiry into the involvement load hypothesis. Education dissertation, Temple University, United States. Retrieved March 15, 2012, from ProQuest Digital Dissertations database. (publication No. 3494138).

Xiao-hui, L., Jun, W., \& Wei-hua, W. (2007). Analysis of schema theory and its influence on reading. US-China Foreign Language, 5(11), 18-21.

Zaghlool, Z. D. (2004). The effect of an instructional programme based on semantic strategies on the learning of lexical items by Jordanian secondary stage students (Unpublished Doctoral Dissertation, Amman Arab University for Graduate Studies, Amman, Jordan).

Zaid, M. (1995). Semantic mapping in communicative language teaching. English Teaching Forum, 33(3), 6-11. 